\title{
Single-centre experience of donation after cardiac death
}

\section{Tim G Coulson \\ BM, BSC \\ Intensive Care Registrar \\ David V Pilche MRCP, FRACP, FCICM Intensive Care Physician, and Adjunct Clinical Associate Professo \\ Shena M Graham RN, CCC, BN Hospital-based Nurse for Organ and Tissue Donation \\ Gregory I Snel \\ MB BS, FRACP, MD Medical Head Lung Transplant Service \\ Bronwyn J Levvey \\ RN, GradDipEpi, BEdStudies, Lung Transplant Servic \\ Coordinator \\ Steve Philpot FCICM Intensive Care Physician \\ Alvin Teo FCICM Intensive Care Physician \\ Andrew R Davies FRACP, FCICM Intensive Care Physician \\ 1 Alfred Hospital, Melbourne, VIC \\ 2 Department of Epidemiology and \\ Preventive Medicine \\ Monash University, \\ Melbourne, VIC. \\ d.pilcher@alfred.org.au}

MJA 2012; 197: 166-169 doi: 10.5694/mjall.11028 $n$ the early years of transplantation, organs were retrieved from patients who were considered to have died by traditional cardiopulmonary criteria (now known as donation after cardiac death [DCD]) or from live donors. ${ }^{1}$ The introduction of diagnostic criteria for brain death provided a more practical and controlled pathway to organ donation. ${ }^{2}$ Donation after brain death (DBrD) allowed organ retrieval without prior cessation of circulation, thus minimising warm ischaemic time and enhancing organ function in the recipient.

Demand for organs for transplantation has grown and outstrips supply. ${ }^{3}$ In recent years some countries have successfully re-implemented DCD to increase overall donor numbers. ${ }^{4}$ Long-term survival of grafts and recipients after DCD kidney and lung transplantation are equivalent to those after $\mathrm{DBrD}^{5-7}$ but DCD liver grafts are still subject to higher risk. ${ }^{8}$ Currently, however, DCD is underused in Australia and practised at few institutions. Given a growing body of evidence, ${ }^{9}$ there appears to be considerable potential for DCD to expand the donor pool.

In Australia, a resurgence of interest in DCD has come with concerns over public and staff perceptions, the possibility of a conflict of interest for clinicians when considering intensive care unit (ICU) treatment withdrawal, ${ }^{10-12}$ the impact on organ function and a potential reduction in the number of $\mathrm{DBrD}$ donors resulting from clinicians or families choosing DCD over DBrD. ${ }^{13}$

The Alfred Hospital is one of 29 tertiary referral hospitals in Australia. It provides cardiothoracic transplantation services for Victoria, South Australia and Tasmania. About 2000 patients are admitted to the ICU per year, of whom about a third are neurosurgical and trauma patients.

In 2004 and 2005, animal models of lung transplantation after cardiac death were investigated at the Alfred Hospital with promising results. ${ }^{14}$ Coincidentally, in 2005, organ donation was requested by the family of a

\begin{abstract}
Objectives: To describe the design, development and implementation of an organ and tissue donation after cardiac death (DCD) program, evaluate its success and assess its impact on tissue and organ availability and the number of donors after brain death.
\end{abstract}

Design, participants and setting: Prospective collection of patient characteristics and outcomes for actual and potential donors from 2000 to 2010 , thus including the 5 years after the implementation of a DCD program at a major Australian tertiary hospital in 2006.

Main outcome measures: The number and type of donors before and after implementation of the DCD program, and subsequent numbers of solid organ and tissue donations.

Results: The DCD program was associated with an increase in overall donor numbers. There were 80 donors ( $20 \mathrm{DCD}$ and 60 donation after brain death [DBrD]) after 2006, compared with $51 \mathrm{DBrD}$ donors in the previous 5 years. Four of the $\mathrm{DBrD}$ donors were patients who were initially considered for DCD. DCD accounted for eight of the total 19 donors in 2009 and seven of the total 23 donors in 2010. There were 62 solid organ and 35 tissue and cornea transplants as a result of the DCD program.

Conclusions: Successful implementation of a DCD program is possible and has led to an increase in overall donor numbers and organs transplanted without any reduction in DBrD donors. The widespread implementation of DCD across Australia may help reduce the shortfall of organs for transplantation.

patient who had severe brain injury but was not brain dead. The family's request could not be facilitated and the patient died without becoming a donor. A complaint was subsequently lodged about the hospital's inability to facilitate organ donation. This provided the impetus to gather interested individuals together, write a guideline and develop an implementation plan for DCD. Although national guidelines for DCD have subsequently been published, ${ }^{15}$ at the time, there were none.

\section{Methods}

Quantitative and qualitative data were collected prospectively on all donors from 2000 onwards and all patients in whom DCD was considered. A review of the DCD program at 5 years had been preplanned, and resulted in this study.

Descriptive methods were used to document the development of the DCD program. Information was gathered from clinicians involved in its implementation. All guidelines produced and subsequently rewritten were reviewed to allow documentation of the program's evolution. Patients' underlying medical conditions, contraindications, investigations, and details about the
DCD process were analysed. The outcomes considered were the number of actual donors and numbers of organs retrieved for transplantation.

\section{DCD guideline development and implementation}

The DCD Guideline Group was founded in 2005. International guidelines, particularly from the United Kingdom and United States where there were active DCD programs, were reviewed.

The ethical implications of DCD and impact of local legislation were considered. To ensure successful implementation of the program, the group aimed to construct a guideline that would be conservative in its approach, acknowledge potential ethical concerns, function within a legal framework and be acceptable to clinicians and the public. Key points in the process were identified and strategies were adopted to deal with potential barriers, as detailed below.

Conflict of interest: The perception of a conflict of interest between the medical staff providing palliative care and the provision of organs for transplantation was addressed. Although the DCD process would determine the timing of withdrawal of cardiorespiratory 
support, other aspects of palliative care should not be altered. It was imperative that cardiorespiratory support would not be withdrawn to remove organs for donation from patients who might otherwise survive, that a patient's death would not be intentionally hastened to ensure that organ donation could proceed and that no patient could be alive when organs were removed. Further, hospital staff and families were to be kept informed, reassured and must support the process. The donation process remained entirely under the control of the attending intensive care physician, with later involvement of the DonateLife coordinator. The transplant team was not involved in medical futility discussions, decisions about the method of treatment withdrawal, or the delivery of terminal sedation.

Prognosis: To confirm medical futility, an opinion from an independent specialist was obtained. This specialist had to agree with the parent medical and the intensive care teams about the patient's prognosis and that withdrawal of cardiorespiratory support was appropriate. The independent specialist's opinion was given independently of any consideration of organ donation.

Request for donation: Initially, only patients whose families raised the topic of organ donation independently were considered, although broaching the topic of DCD was deemed acceptable if the patient was already listed on the Australian Organ Donor Registry. However, in April 2010, the guideline was changed to allow medical staff to raise organ donation when appropriate. Two intensive care specialists: The primary intensive care specialist undertook all discussions about prognosis with the family, supervised the provision of palliative care and prescribed the method of withdrawal of life support (eg, extubation, cessation of inotrope therapy) in accordance with their usual practices. A second intensive care specialist, who had no role in providing palliative care or withdrawing cardiorespiratory support, was required to ensure all aspects of the guideline were followed and to discuss the organ donation processes with the family if necessary.

Medical suitability: In addition to pre-existing selection criteria for organ donors, only ventilated patients within the ICU were considered. Initially, an age limit of 55 years was applied. However over the next 5 years, this was
1 The Alfred Hospital donation after cardiac death (DCD) program flow chart*

\section{thentined DCD Pathway}

\begin{tabular}{l} 
Roles and \\
Responsibilities \\
Primary Intensivist \\
Prognosis \\
End of life care \\
Coroner notification \\
Patient \& next of kin wishes \\
Statement of identification \\
Mechanism of withdrawal \\
Declaration of death \\
Death certificate \\
\hline Second Intensivist \\
DCD guideline compliance \\
Talk to next of kin (if required) \\
\hline Donor Coordinator \\
Coroner \\
Retrieval teams \\
Designated Officer \\
Consent paperwork \\
Timing of withdrawal \\
Operating room meeting \\
ICU meeting if required \\
\hline
\end{tabular}

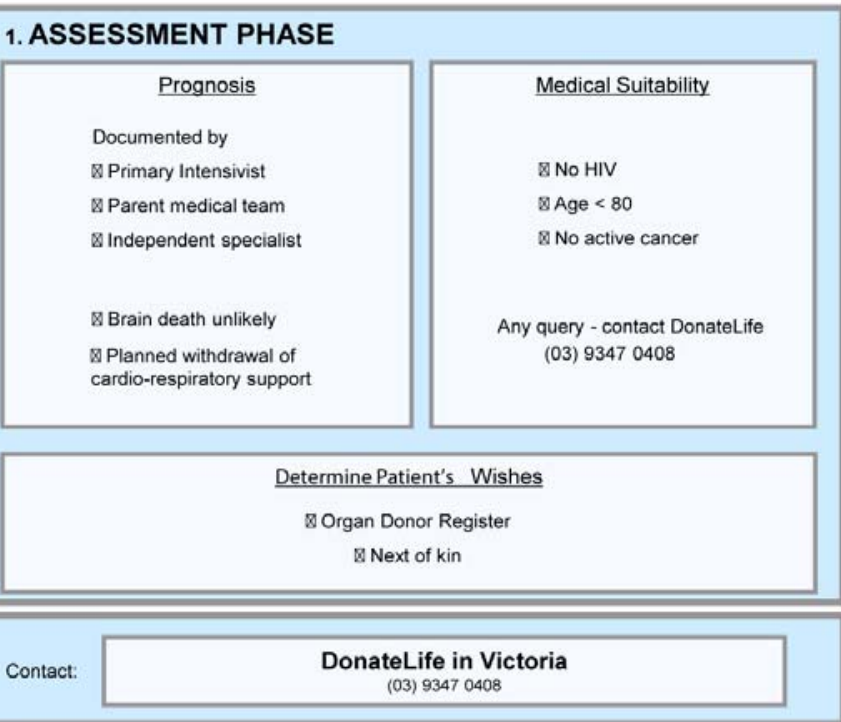

\section{PLANNING PHASE}

Liaison with operating room $\&$ retrieval teams

Inform Coroner (if required) and Designated Officer

Donor assessment and support (may take $>12$ hours)

3. WITHDRAWAL PHASE
\begin{tabular}{|l|}
\hline Withdrawal of cardio-respiratory support ( $\mathrm{SaO}_{2}$ and arterial line required $+i-\mathrm{ECG}$ ) \\
\hline Cessation of circulation (Pulseless arterial line) \\
\hline FIVE minute observation period \\
\hline Certification of death by ICU doctor \\
\hline Authorisation from Designated Officer \\
\hline If death > 90 minutes after withdrawal, organ donation may be abandoned \\
\hline Transfer of body to operating room (within 10 minutes) \\
\hline
\end{tabular}

\section{OPERATING ROOM PHASE}

Organ preservation processes (e.g. heparin) occur after death \& usually in OR

Organ donation surgery

* This flow chart summarises the current process for DCD at the Alfred Hospital. The guideline was completed in April 2006 and was followed by an education and implementation program aimed at intensive care unit and operating theatre staff. The Alfred DCD guideline has been updated a number of times since its initial publication based on local, national and international feedback.

increased from 55 to 65 years and then to 75 years. ${ }^{16}$ Initially, only lung donation was considered because of a lack of on-call access to renal retrieval services. In 2007, kidney donation, and in 2008, donation of any other suitable organ (eg, liver or pancreas) were included.

Antemortem interventions: Investigations to determine organ suitability and recipient compatibility were conducted after consent was obtained. Procedures that were not part of routine palliative care and potentially harmful to dying patients (such as administration of intravenous anticoagulants, bronchoscopy or insertion of perfusion cannulae before death) were not permitted.

Certification of death: Placement of an invasive arterial line and oxygen 
2 Number of donors at the Alfred Hospital each year, 2001-2010

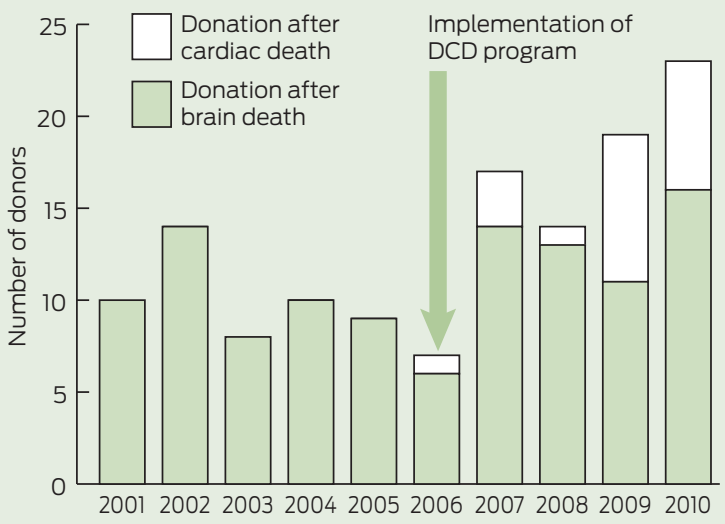

3 Outcomes of organ donation from potential donation after cardiac death (DCD) donors at the Alfred Hospital from 2006 when the DCD program was implemented until 2010*

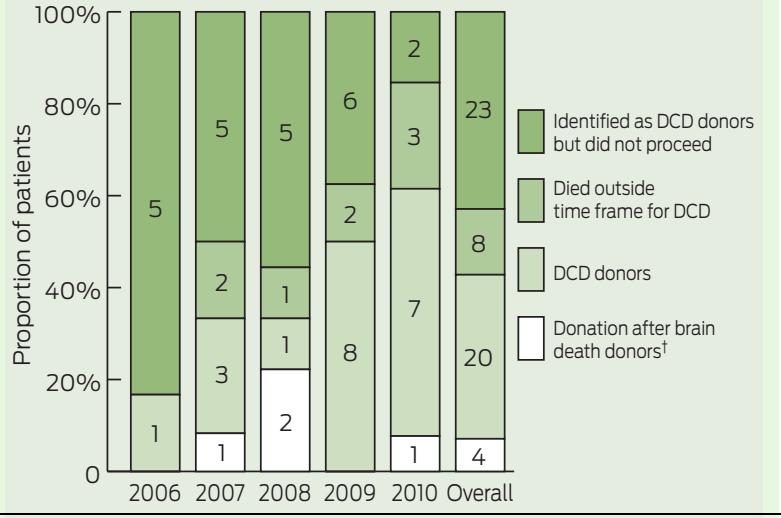

*Actual numbers of patient for each year and overall shown on figure. $\dagger$ Initially identified during consideration of DCD.

4 Organs and tissue successfully retrieved and transplanted as a result of the Alfred Hospital donation after cardiac death (DCD) program

\begin{tabular}{lccc} 
Organs transplanted & $\begin{array}{c}\text { Transplants } \\
\text { from } \\
\text { DCD donors }\end{array}$ & $\begin{array}{c}\text { Transplants from } \\
\text { DrD donors identified } \\
\text { through the } \\
\text { DCD program }\end{array}$ & Total \\
\hline Lungs & 13 & 3 & 16 \\
Kidneys & 31 & 8 & 39 \\
Heart & 0 & 2 & 2 \\
Pancreas & 0 & 1 & 1 \\
Liver & 1 & 3 & 4 \\
Total solid organs & 45 & 17 & 62 \\
Cornea/tissue donations & & & 35 \\
\hline
\end{tabular}

$\mathrm{DBrD}=$ donation after brain death.

saturation monitoring were mandatory for all cases. Electrocardiographic (ECG) monitoring was used at the discretion of the primary intensive care physician. Death was declared 5 minutes after cessation of circulation (as evidenced by complete loss of pulsatility of the arterial line). A further 5 minutes was allocated for families to spend with their relative after declaration of death.
However after the first year, the mandatory additional 5 minutes of "family time" was removed, as we found families never used it.

Logistics: Considerable planning went into logistics. Processes and roles of key staff are summarised in Box 1. A team meeting with all relevant ICU, theatre, surgical, anaesthetic, medical, nursing and support staff was planned before withdrawing cardiopulmonary support to discuss all aspects of the process. Follow-up meetings were held 24-48 hours after every case of DCD during the first 2 years, and then when required thereafter.

\section{Ethics approval}

The study was approved by the Alfred Hospital Ethics Committee (Low Risk Ethics Approval Number: 232/11).

\section{Results}

\section{DCD program outcomes}

The first case of DCD (Australia's first lung transplantation from a donor after cardiac death) occurred a month after the guideline was implemented. Between 2006 and 2010, there were 55 patients for whom DCD was initially discussed. Of these, 28 patients underwent withdrawal of cardiorespiratory support in anticipation of DCD, and 20 of those became donors.

Box 2 shows the total number of donation after brain death and DCD donors over the past 10 years at the Alfred Hospital, with DCD accounting for eight of the 19 donors in 2009 and seven of the 23 donors in 2010. During the first 5 years of the program, the Alfred Hospital contributed 20 of the 54 DCD donors in Victoria, comprising $12.4 \%(20 / 161)$ of all DCD donors in Australia. There was no concurrent reduction in the number of $\mathrm{DBrD}$ donors. Four patients became $\mathrm{DBrD}$ donors while being considered for DCD. In one case, a patient became brain dead, but the DCD pathway was followed owing to family insistence. One DCD donor was probably brain dead, but this was not recognised before withdrawal of cardiorespiratory support. Box 3 shows actual DCD donors per year as percentages of all patients for whom DCD was considered.

Of Australia's total organ donors, $6.6 \%(80 / 1215)$ were identified at the Alfred Hospital in 2006-2010, compared with 5.1\% (51/992) in 2000-2005, before the DCD program was implemented $(P=0.23)$. Overall admissions to the ICU at the Alfred Hospital did not change significantly over the 10 years, remaining stable at about 2000 per year. Implementation of the DCD program resulted in 62 organ transplants, 17 of these organs came from the four donors who were brain dead and who were identified through the DCD program (Box 4).

\section{Acceptance of the program}

Acceptance by medical and nursing staff has been progressive and there is evidence of a "learning curve" with the DCD program. Each year a larger proportion of patients in whom DCD was considered had cardiorespiratory support withdrawn in anticipation of DCD (Box 3 and Box 5). However, the ability to predict who will die within a time frame permitting successful donation remained unchanged.

Families initiated discussions about donation in all but four cases. Two families would not accept donation through the $\mathrm{DBrD}$ pathway, but were happy to progress to donation through DCD. However, two of the 55 families withdrew their consent for donation stating that the DCD process was unacceptable (for unknown reasons). Two complaints were received from families about organ donation. Both related to the hospital's inability to offer organ donation (the first discussed earlier, the second resulting from a failure by the hospital to facilitate kidney donation because the guideline at the time specified that only lung donation was available).

All families agreed to the required investigations and monitoring. In three cases these necessitated insertion of a new arterial line specifically for accurate determination of death. ECG monitoring was used in most cases. In one case, however, this led to confusion and family distress when the arterial line became pulseless 2 minutes before electrical standstill.

\section{Discussion}

We describe the implementation and outcomes of a DCD program in a major tertiary hospital. This program has been associated with an increase in overall donor numbers without a reduction in organ and tissue donations after brain death. 


\section{Reasons patients considered for donation after cardiac death (DCD) did not go on to become donors}

Reasons*

No. of patients

\begin{tabular}{|c|c|}
\hline DCD discussed, but did not proceed to withdrawal of cardiorespiratory support in anticipation of DCD (breakdown below) & $\begin{array}{c}8 \\
23\end{array}$ \\
\hline Independent specialist did not think prognosis was futile & 2 \\
\hline Survived to hospital discharge & 1 \\
\hline Died during further observation period & 1 \\
\hline Patients for whom donation was raised by the family but then declined & 8 \\
\hline Not prepared to wait for time frame required to organise donation & 4 \\
\hline Patient became brain dead & 1 \\
\hline "Didn't like DCD" & 2 \\
\hline Unknown & 2 \\
\hline Patients outside of Alfred Hospital DCD guideline at the time of referral & 6 \\
\hline Too old & 2 \\
\hline Not asked but otherwise medically suitable & 3 \\
\hline Suitable for kidney donation but the hospital was only offering lung retrieval at the time & 1 \\
\hline Patient receiving palliative care on general ward when patient and family request donation & 1 \\
\hline Transfers from other hospital for purposes of assessment for DCD donation & 0 \\
\hline Patients with a contraindication to donation discovered during work-up & 7 \\
\hline Organ function not good enough & 4 \\
\hline Donor had hepatitis $C$ and there were no suitable recipients & 2 \\
\hline Discovery of a previously unknown medical condition (eg, cancer) & 2 \\
\hline
\end{tabular}

* Not mutually exclusive.

The Alfred Hospital DCD guideline continues to differ slightly from the national guideline for DCD produced in $2010^{15}$ (eg, in not allowing antemortem interventions such as heparin infusion or bronchoscopy). Victoria remains reliant on individual hospitals developing policies which best suit local practice rather than applying a statewide policy.

Although medical staff initially raised concerns, DCD is now an accepted pathway to organ donation. Determination of a patient's wishes about organ donation is considered a routine part of end-of-life care and one that is independent of the presence or likelihood of brain death. Concerns about a potential conflict of interest have been allayed by providing a specialist opinion about prognosis and the involvement of two intensive care specialists to separate the palliative care and organ donation processes. Remarkably, the requirement for an independent specialist opinion led to the re-institution of active therapy in one patient who was about to have cardiorespiratory support withdrawn. He subsequently survived to return to work, albeit with some neurological disability.

The implementation of the DCD program was also associated with increased numbers of $\mathrm{DBrD}$ donors. This was partly owing to patients who became brain dead while being considered for DCD (all of whom would have previously died without their wishes for donation being fulfilled) but may also have been the result of increased awareness of donation by medical staff and the public.

Limitations of our retrospective study should be recognised. Processes implemented and evaluated at the Alfred Hospital may not be applicable to all hospitals. It is possible that there were other patients in whom DCD was considered, but who did not become donors, and who were not brought to the attention of the donation team or study investigators.

Although absolute numbers of donors are relatively small, the potential impact on available organs for transplantation is high. Our study shows that introduction of DCD at one tertiary hospital can lead to increased numbers of organs available for transplantation without any reduction in $\mathrm{DBrD}$ donations. The National protocol for donation after cardiac death, published in 2010,15 now provides a framework to develop similar programs. We believe all hospitals in Australia should investigate their potential for DCD.

Acknowledgements: We thank the Alfred Hospital medical, nursing and administrative staff, the legal support team, the Donatelife team, staff of the Victorian Institute of Forensic Medicine and the donor families.

Competing interests: David Pilcher is a Medical Advisor to DonateLife in Victoria.

Received 6 Aug 2011, accepted 22 Jan 2012

1 Linden PK. History of solid organ transplantation and organ donation. Crit Care Clin 2009; 25: 165184, ix.

2 Potts JT, Herdman R. Non-heart-beating organ transplantation: medical and ethical issues in procurement. Washington, DC: National Academies Press, 1997.

3 Excell L, Hee K, Russ G. Australia and New Zealand Organ Donation Registry 2010 Report. Adelaide: ANZOD Registry, 2010. http://www.anzdata.org.au/ anzod/vl/AR-2010.html (accessed Sep 2011).

4 Mañalich R, Paez G, Valero R, Manyalich M. IRODaT: the International Online Registry for Organ Donation and Transplantation 2007. Transplant Proc 2009: 4l:2030-2034.

5 Summers DM, Johnson RJ, Allen J, et al. Analysis of factors that affect outcome after transplantation of kidneys donated after cardiac death in the UK: a cohort study. Lancet 2010; 376:1303-1311.

6 Snell GI, Levvey BJ, Oto T, et al. Early lung transplantation success utilizing controlled donation after cardiac death donors. Am J Transplant 2008; 8: 1282-1289.

7 De Oliveira NC, Osaki S, Maloney JD, et al. Lung transplantation with donation after cardiac death donors: long-term follow-up in a single center. J Thorac Cardiovasc Surg 2010; 139:1306-1315.

8 Reich DJ, Hong JC. Current status of donation after cardiac death liver transplantation. Curr Opin Organ Transplant 2010; 15: 316-321.

9 Snell GI, Levvey B, Oto T, et al. Effect of multiorgan donation after cardiac death retrieval on lung performance. ANZ J Surg 2008; 78: 262-265.

10 Sayegh MH, Carpenter CB. Transplantation 50 years later--progress, challenges, and promises. N Engl J Med 2004; 351: 2761-2766.

11 Snell GI, Levvey BJ, Williams TJ. Non-heart beating organ donation. Intern Med J 2004: 34:501-503.

12 Mandell M, Zamudio S, Seem D, et al. National evaluation of healthcare provider attitudes toward organ donation after cardiac death. Crit Care Med 2006; 34: 2952-2958.

13 Nath J, Mellor SJ. Organ transplantation after cardiac death. Lancet 2011; 377: 203.

14 Snell GI, Oto T, Levvey B, et al. Evaluation of techniques for lung transplantation following donation after cardiac death. Ann Thorac Surg 2006; 81: 2014-2019.

15 National Health and Medical Research Council. National protocol for donation after cardiac death Canberra: Australian Organ and Tissue Donation and Transplantation Authority, 2010. http:// www.donatelife.gov.au/the-authority/publications (accessed Sep 2011).

16 Snell GI, EsmoreDS, Westall GP, et al. The Alfred Hospital lung transplant experience. Clin Transp 2007: 131-144. 